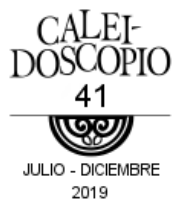

Reseñas

\title{
Reseña de Garda (2018) Nuevas habilidades para los hombres. Para varones que desean construir la equidad y la igualdad en sus relaciones de pareja y familiares
}

Review of Garda (2018) Nuevas habilidades para los hombres. Para varones que desean construir la equidad y la igualdad en sus relaciones de pareja y familiares

CÉSAR EDGARDO ZÚÑIGA ARAIZA ${ }^{1}$

Garda, Roberto (2018). Nuevas habilidades para los hombres. Para varones que desean construir la equidad y la igualdad en sus relaciones de pareja y familiares. Ciudad de México: Secretaría de Desarrollo Social de la Ciudad de México; Hombres por la Equidad, A. C.

Esta es una reseña sobre el cuadernillo de trabajo titulado Nuevas habilidades para hombres. Para varones que desean construir la equidad y la igualdad en sus relaciones de pareja y familiares, que ha sido escrita como propuesta de intervención por el autor Roberto Garda, director de Hombres por la Equidad A. C., y quien tiene una amplia experiencia con programas de atención a hombres que ejercen violencia de pareja y

${ }^{1}$ jesus_cesar80-2@hotmail.com 
de género. Además de presentar el texto, trato de plantear algunos puntos que en la propia experiencia han surgido y que al parecer pueden facilitar la comprensión y la reflexión de la presente reseña; con ello se presentan a manera de comentarios que se ponen a consideración de la o el propio lector.

En dicho cuadernillo se pretende ofrecer un método distinto para actuar de forma equitativa frente a los conflictos con la pareja, hijas e hijos y otros familiares; a la vez, comprender qué significa en la práctica ejercer la equidad ante momentos de tensión, a esto el autor lo denomina actitud de equidad. Son estos dos objetivos los que se abordan en el cuadernillo y sobre ellos se basa para ofrecer el método con el que ha estado trabajando con los varones que han asistido a los grupos de reflexión.

Para empezar a exponer su método de intervención, Garda señala que es importante que los hombres reconozcamos que en nuestras interacciones nos vivimos con las prácticas de solucionar los conflictos de manera violenta y equitativa a la vez, es decir, los hombres, dependiendo del problema o del conflicto y con quien es llevado a cabo, nos movemos en estos dos niveles de tratar de solucionarlos, a veces de manera violenta, a veces de manera equitativa, ambas formas interaccionan en las relaciones y ambas son puestas en práctica en la cotidianidad. Postula que esta dinámica es más un aprendizaje que los hombres hemos tenido desde nuestras relaciones en la familia de origen, así como es reforzada por las presiones o tensiones que se ponen en juego por la colusión que otros varones ejercen sobre nuestros modos de relacionarnos con las mujeres y con otros varones.

Para fortalecer las conductas equitativas es necesario estar atento a siete ámbitos: el manejo de las emociones, 
el manejo de los pensamientos, el ejercicio de la comunicación, la conducta o conductas ejercidas durante los conflictos, las reacciones del cuerpo, la historia de vida y las presiones de las creencias sociales

Con base en el análisis de los conflictos previos con sus parejas, con otras mujeres o con sus hijas e hijos, se va ejercitando la reflexión de lo general, es decir, de lo que el hombre hace para enfrentar el conflicto a través del cuestionamiento de cada uno de los siete ámbitos hasta lo particular, es decir, ir visibilizando, exponiendo y resignificando en función de la actitud de la equidad cada uno con sus experiencias personales del ejercicio de la violencia.

Garda recomienda que para tener mejores resultados en el uso de este método, los hombres deben asistir a los grupos de reflexión, donde las experiencias de violencia de otros hombres y la guía de los varones que apoyan en llevar a cabo la reflexión, facilitarán y mejorarán las maneras distintas del abordaje del conflicto sin el uso de la violencia, dejando a ésta como único mecanismo aprendido para solucionar los problemas.

Además, Garda expone dos aspectos centrales que se ponen a prueba para que los hombres fortalezcamos las conductas equitativas: a) la voluntad de cambio, es decir, querer, desear y decidir cambiar la manera de solucionar los conflictos, para facilitar la actitud de la equidad de género, y b) las habilidades que los hombres tengamos para comunicarnos y expresar lo que nos preocupa, es decir, si los hombres decidimos comentar lo que pensamos, sentimos y compartirlo a las y los demás eso que nos preocupa, seremos más susceptibles al cambio, a la actitud de la equidad.

Al parecer, lo que sustenta el método expuesto en el cuadernillo es la reflexión y el cuestionamiento de los siete 
ámbitos y los dos aspectos que ponen a prueba a los varones para lograr la actitud de la equidad de género.

Con ello, Garda menciona que para que este método pueda lograr mejores resultados en los varones se deben exponer a los mismos ciertos facilitadores que serán de mucha utilidad para que el proceso de cambio pueda generar nuevas maneras de relacionarse con las y los demás:

1. Reflexionar sobre la ambivalencia del poder masculino. El uso del poder de forma jerárquica y abusiva facilita un sentido ambivalente de solucionar los problemas y es la violencia el mecanismo más común para hacer "valer" este Poder. Aquí se expone que es en las diferencias de identidad, vale decir, diferencias no tradicionales a un significado machista o masculino, lo que facilita que otras identidades o maneras diferentes de vivirse, expresarse, ser, a la masculinidad tradicional, deriven en castigos o agresiones y en desigualdades sociales que se convierten en estructurales: esto es una cultura que maximice lo significante como masculino y denigre o no visibilice lo significante como femenino, la cultura masculina -valga decir machista o patriarcal- es la que es responsable de influir y educar a los hombres para que ejerzan de forma frecuente la violencia hacia las mujeres y hacia aquello que ha sido definido como femenino. Al apoyar a los varones para que se cuestionen dicha ambivalencia de poder en sus relaciones cotidianas y en la manera de solucionar los conflictos, se espera una resignificación de esta masculinidad tradicional y mejoras en la interacción con otras y otros.

2. Reflexionar sobre la necesidad de una cultura de respeto a las diferencias. Aquí se plantea cuestionar la diversidad de formas de ser y expresarse, desde las diferentes orientaciones sexuales, hasta la construcción de 
valores sociales y personales que incluyan el respeto y fomenten los derechos humanos básicos para poder ser diverso a la masculinidad tradicional. Esto implica los cuestionamientos del empoderamiento de la pareja y las mujeres como mecanismo de equidad, más que de igualdad, ya que tanto en las instituciones como en la individualidades se requieren hombres que piensen diferente su identidad a la masculinidad tradicional, no como efecto nocivo, sino como efecto propositivo hacia las mejoras en los espacios y las dimensiones donde convivimos con otras y otros.

3. Cuestionar la idea de definirnos. Garda menciona que la masculinidad tradicional imprime un poder autoritario que exige que nos definamos de una forma u de otra para controlarnos. Y comenta que ese es el problema central que los hombres tenemos, al no resignificar o al no renunciar a la forma de masculinidad tradicional ya que esto nos limita en cuanto a posibilidades de cambio, y en cuanto a posibilidades de diversidad. Comenta que es importante cuestionarnos esta enajenación con este mandato machista tradicional de "deber ser" de una manera y sólo por medio de la reflexión y del cuestionamiento de todas estas normas de género que a los hombres se nos han impuesto a través de los mandatos tradicionales masculinos, es como podremos entender mejor nuestra historia de vida, que podría ubicarnos en esta ambivalencia de poder o que podría darnos la posibilidad de diversificar nuestras maneras de relacionarnos y llegar a esta actitud de equidad con otras y otros.

Por último, Garda menciona: "No proponemos ni nuevas masculinidades, ni un machismo light en ella, proponemos que los hombres definan y nombren sus identidades distintas desde el ejercicio de la igualdad con la pareja y 
los hijos e hijas, así como con la comunidad". Con ello se suma a lo que ya ha postulado anteriormente el psicólogo español Luis Bonino:

El poder configurador de la $\mathrm{MH}$ se hace evidente en la vida de los hombres contemporáneos no tanto en su discurso, sino en sus prácticas; no tanto en sus comportamientos aislados, sino en su posición existencial, modo de estar e incapacidad para el cambio en lo cotidiano; no tanto en sus momentos estables, sino en las situaciones críticas; en su identidad representacional (imagen de sí) pero especialmente en la funcional (lo que hacen) (2002, p. 8).

Como ya se ha mencionado, estas ideas expuestas sobre este Cuadernillo, son sólo a manera de reseña y de presentar dicho método para lograr la equidad en las relaciones interpersonales. No fue el objetivo hacer una crítica a las ideas o al método, sino guiar al lector sobre esta metodología y exponer que en la práctica y en la búsqueda de formas para intervenir con los varones que ejercen violencia de género aún hay mucha tarea y trabajo para encontrar los procesos que mejor ayuden a las permutas para los hombres que realmente deciden un cambio sobre sus maneras de abordar un conflicto sin el uso de la violencia.

Sistematizar los resultados de dichos métodos y las experiencias de los varones que han pasado por los grupos de reflexión sería una tarea que aún está en deuda con los mismos hombres y con sus parejas para tratar de dar cuenta sobre los hábitos o nuevas habilidades que les permita solucionar sus problemas de manera equitativa y con perspectiva de género. 
REFERENCIAS

Bonino, L. (2002). Masculinidad hegemónica e identidad masculina. Dossiers Feministes, 6, 7-35. Recuperado de http://www.e-revistes.uil.es/index.php/dossiers/artic le/view $/ 735 / 635$

CÓMO CITAR ESTA RESEÑA

Zúñiga Araiza, C. E. (2019). Reseña de Garda (2018) Nuevas habilidades para los hombres. Para varones que desean construir la equidad y la igualdad en sus relaciones de pareja y familiares. Caleidoscopio - Revista Semestral de Ciencias Sociales y Humanidades, 23(41), 259-265. doi:10.33064/41crscsh2133 